\title{
Comparative analysis of the stock quotes dynamics for IT-sector and the entertainment industry companies based on the characteristics of memory depth
}

\author{
Nataliia Maksyshko ${ }^{1, *}$ and Oksana Vasylieva ${ }^{1, * *}$ \\ ${ }^{1}$ Zaporizhzhia National University, 66 Zhukovskoho Str., Zaporizhzhia, 69600, Ukraine
}

\begin{abstract}
The article is devoted to the study and comparative analysis of the stock quotes dynamics for the world's leading companies in the IT sector and the entertainment industry. Today, these areas are developing the fastest and most powerful, which attracts the attention of investors around the world. This is due to the rapid development of digital communication technologies, the growth of intellectualization and individualization of goods and services, and so on. These spheres have strong development potential, but the question to how their companies' stock quotes respond to the impact of such a natural but crisis phenomenon as the COVID19 pandemic remains open. Based on the nonlinear paradigm of the financial markets dynamics, the paper considers and conducts a comprehensive fractal analysis of the quotations dynamics for six leading companies (Apple Inc., Tesla Inc., Alphabet Inc., The Walt Disney Company, Sony Corporation, Netflix) in this area before and during the COVID-19 pandemic. As a result of the application of the rescaled range analysis (R/S analysis), the presence of the persistence property and long-term memory in the stock quotes dynamics for all companies and its absence in their time series of profitability was confirmed. The application of the method of sequential $\mathrm{R} / \mathrm{S}$ analysis made it possible to construct fuzzy sets of memory depths for the considered time series and to deepen the analysis of the dynamics due to the quantitative characteristics calculated on their basis. Taking into account the characteristics of memory depth in the dynamics of quotations made it possible to conduct a comparative analysis of the dynamics, both under the influence of the natural crisis situation and in terms of investing in different terms. The peculiarities of the delayed profitability dynamics of quotations for each of the companies are also taken into consideration and compared. The developed recommendations can be used in investment activities in the stock market.
\end{abstract}

\section{Introduction}

Trading in financial instruments on stock exchanges is increasingly becoming a source of income for various investors. At the same time, investors face the problem of choosing financial instruments in which to invest. For the investor, effective management of their financial resources now - means to get additional benefits in the future. But in order to get these benefits, they need to compare financial instruments and choose the most profitable and least risky among them.

The issue of analyzing the stock markets dynamics in order to develop practical recommendations for the investor is not new, but it remains relevant and extremely important. Development of investment strategy and awareness of prospects and risks of specific investment instruments is the key to successful investment activities.

For comparative analysis, traditionally, statistical characteristics of dynamics are used. Traditionally, statistical methods have been used to confirm the efficient market hypothesis [1]. For example, in [2]: Kolmogrov-Smirnov and Shapiro-Wilk tests; a run test and an auto-correlation

\footnotetext{
*e-mail: maxishko@ukr.net

**e-mail: oksanabay@ukr.net
}

test are used to check the randomness and the normality of the data. In [3] there is applied a rolling variance ratio test; in [4] European stock markets are tested by a runs test and joint variance ratio tests. In the study [3] the French stock market is considered to change its properties from efficient to adaptive.

An alternative theory of financial markets is the fractal market hypothesis [5], which considers markets as complex nonlinear systems in which randomness and hidden patterns interact, resulting in the dynamics of financial instruments has a fractal nature and the property of persistence (the presence of long-term memory). Methods of nonlinear dynamics are considered as relevant tools of its research. Therefore, recently more and more attention is paid to the study and application of these methods.

The most popular method of studying the fractal properties of dynamics is the Hurst exponent (R/S analysis) [5]. The paper [6] provides an excursion into the research of scientists on the application of the Hurst exponent to analyze the dynamics of capital markets.

Along with the Hurst exponent for the study of financial markets and, in particular, stock markets, the following indicators are used: Lyapunov exponent (indicator of nonlinear dynamics) to diagnose the crash of stock mar- 
kets [7], Shannon information entropy [8, 9], Renyi entropy [9], the Hurst-Holder exponent [10], local Whittle estimator [11]. The presence of fractal properties in the dynamics of financial markets is also investigated by calculating the Hausdorff dimension and applying the MittagLeffler functions [12].

In particular, in the works $[13,14]$, a method of sequential $\mathrm{R} / \mathrm{S}$ analysis is proposed, which allows not only to establish the presence of long-term memory in the time series, but also to evaluate its quantitative and qualitative characteristics. The authors show that for the dynamics of different financial instruments that have long-term memory, memory characteristics may differ.

The authors also consider the use of different tools of nonlinear dynamics in terms of different stock markets and their segments. For example, in $[15,16]$ - the stock markets of individual countries are considered, in [17] - quotations of shares of certain companies, in [18] - multifractality the autocorrelations in stock portfolio returns is studied and other.

The research and comparison object of this work is the dynamics of shares quotations of leading companies in the IT sector and the entertainment industry. Today, these areas are developing the fastest and most powerful, which attracts the attention of investors around the world. This is due to the rapid development of digital communication technologies, the growth of intellectualization and individualization of goods and services, and so on. These areas have strong development potential, but the question of how stock quotes in this area respond, for example, to the impact of such a natural but crisis phenomenon as the COVID-19 pandemic remains open.

The hypothesis of this work is that the characteristics of long-term memory can also be used for comparative analysis and development of recommendations for investors operating in the stock market. The purpose of this work is to study the characteristics of the memory depth for the stock quotes dynamics of selected companies, their stability under the influence of such a crisis as the global COVID-19 pandemic, conducting a comparative analysis based on them and developing recommendations for investors.

\section{Materials, methods and results}

\subsection{Materials and methods}

Since the behavior of stock prices in the stock markets is mostly not normally distributed or close to normal distribution [5], after testing for deterministic chaos and proof of its fractal nature, it is advisable to use fractal analysis methods for its study. Such methods include the method of the Rescaled range or $\mathrm{R} / \mathrm{S}$ analysis of Hurst (denote it A_1) [5] and the method of sequential R/S analysis (A_2) [13].

Let the time series (TS) $X$ be considered. The result of applying method $A_{-} 1$ is to determine the Hurst exponent $(H)$ and check its significance based on the application of the mixing test.
The value of the Hurst exponent $H \in[0 ; 1]$ determines the presence of certain properties of the dynamics: the value of $H \in(0 ; 0.5)$ corresponds to the antipersistent or ergodic TS; the value of $H=0.5$ (and in its vicinity) indicates a random TS, in which events are random and uncorrelated, the present does not affect the future; the value of $H \in(0.5 ; 1]$ indicates that the TS is persistent or trendresistant, characterized by the presence of long-term memory. The closer the value of $H$ to 1 , the more correlated the levels of the series.

Recall that the essence of the method of the Rescaled range exponent of Hurst $A_{-} 1$ is to construct the R/S trajectory for the TS $X$ and determine the angle of the linear trend, built on its (R/S trajectory) starting points. At some value of $k=k_{0} \mathrm{R} / \mathrm{S}$ trajectory changes its slope quite sharply, i.e. at the point $\left(x_{k_{0}}, y_{k_{0}}\right)$ the trajectory receives a significant in absolute value negative gain $\delta_{k}=y_{(k+1)}-y_{k}$ - there is a break from the trend and there is no return to the previous trend. It is assumed that at the point $k_{0}$ the effect of "long-term memory of the beginning of the series" dissipates. That is, the "breakdown of the trend" demonstrates the loss of memory about the initial conditions, and also signals (possibly with a lag, ie with some delay) the exhaustion of the cycle or quasi-cycle contained in the initial segment of this TS. According to [5], we adhere to the statement that after the end of the cycle (quasicycle) the memory about the initial conditions is lost, ie the long-term correlation of the following observations with respect to the initial one is lost. However, based on the peculiarities of the construction of the R/S-trajectory [5], the method of the R/S analysis of Hurst $A_{-} 1$ provides only (statistically) the average characteristic of the trend stability of the TS $X$ as a whole and does not take into account the changing dynamics during the whole observation period.

However, the method of sequential R/S analysis $A \_2$ [13] by modifying the scheme of construction of R/Strajectory, allows to take into account the changing nature of the dynamics, to identify many cycles (quasi-cycles) that are characteristic of the studied TS, and ensure a more detailed assessment of the memory depth from the beginning of this TS.

Performing an iterative procedure (method $A \_3$ ) using method $A \_2$ and detecting the point of memory loss at the beginning of the time series for a set of nested segments $X=X^{0} \supset X^{1} \supset \ldots \supset X^{r} \supset X^{n-3}$ (a family of time series differing by the starting point) allows to estimate the memory depth as a fuzzy set "memory depth of the TS as a whole" [14]. Note that the transition from a "clear" estimate (based on probability and requiring statistical significance) to a fuzzy estimate (non-additive measure) is due to the availability of data for which these requirements are not met.

According to $[13,14]$ the concept of "memory depth of TS $X$ ” is defined as a discrete fuzzy set (FS)

$$
L(X)=\left\{\left(l_{i}, \mu_{L}\left(l_{i}\right)\right) ; l_{i} \in N\right\}, \mu_{L}: N \longrightarrow[0 ; 1],
$$

where $N=\left\{l_{i}, i=1,2, \ldots\right\}$ - natural numbers set - set of basic values for memory depth, 
$\mu_{L}\left(l_{i}\right)=\mu\left(l_{i}\right)-$ the value of the membership function, which determines the degree of belonging of a natural number $l_{i}$ ("depth $l_{i}$ ") to a fuzzy set $L(X)$. The function $\mu_{L}\left(l_{i}\right)$ displays the base value $l_{i}$ in the interval $[0 ; 1]$ and displays the degree of possibility (confidence measure) in relation to the membership of the element $l_{i}$ fuzzy set of memory depth $L(X)$.

The carrier of the fuzzy set $L(X)$ is the set "supp" $L(X)=L^{0}=\left\{l_{i} \in N, i=1,2, \ldots .: \mu_{L}\left(l_{i}\right)>0\right\}$. Therefore, we finally consider the fuzzy set of memory depth of the time series $X$ as a whole in the form

$$
L(X)=\left\{(l, \mu(l)), l \in L^{0}\right\} .
$$

Important characteristics based on the use of fuzzy memory set (2) are given in [14]. In this paper, for a comparative analysis of price dynamics, the following characteristics are used: $l_{\max }-$ the greatest value of the memory depth encountered:

$$
l_{\max }=\max _{l \in L^{0}} l,
$$

$l_{m c}$ - the memory depth value that has the largest value of the membership function $\mu(l)$ :

$$
\mu\left(l_{m c}\right)=\max _{l \in L^{0}} \mu(l)
$$

$l_{g c}$ - the gravity center of the fuzzy set $L(X)$ as a whole - is obtained using the defuzzification procedure:

$$
l_{g c}=\frac{\sum_{l \in L^{0}}[l \cdot \mu(l)]}{\sum_{l \in L^{0}} \mu(l)},
$$

$H_{\text {entr }}$ - information entropy indicator for the fuzzy set of memory depth $L(X)$ - used to assess the uncertainty degree regarding the variety of TS's behavior variants:

$$
H_{\text {entr }}=-\sum_{l \in L^{0}} \mu(l) * \log _{2} \mu(l) .
$$

Note that the scale for estimating the degree of uncertainty is considered to be ordinal by type.

Thus, the use of the selected considered characteristics of the memory depth for time series allows to deepen the comparative analysis of the stock prices dynamics for companies in the IT sector and the entertainment industry.

\subsection{Stock market overview and input data}

Today in the modern stock market there are separate sectors, which on the basis of information from sites [19, 20], are distributed according to the level of volatility.

The names of the companies for reduction are given according to their stock tickers.

Very high volatility: energy sector - oil (PZE, EC, HOM), gas (GAS, WGR, SPH), coal (BTU, ACI, MEE), alternative fuel (PTOI, GRPEF, BLDP); Industrial sector - industrial electronics (EDIG, SIRC, RGSE), industrial products (BOOM, PLPC, TPIC), machinery (SOHVY, CTEQF, PERT), aviation and space (Boeing, Generaldynamics, Tesla).
High volatility: Basic resources and materials gold (HGLC, RMRK, NSRPF), metals (ACH, USNZY, GGIFF), chemical products (SKVI, LPAD, NL), forest resources and paper production (AZFL, NKSJF, FBI); Financial services - brokers (GS, LEH, BSC), banks (C, USB, NYB), insurance companies (AIG, XL, JH), management companies (WM, JNS, JNC), stock exchanges (CME, NYX, ICE), mortgage (FNM, FRE, AHM); Media / Entertainment - Worldflix Inc (WRFX), Dolby Laboratories (DLB), Disney (DIS), New-York times (NYT), Netflix (NFLX).

Average volatility: Retail and wholesale - clothing (DEST, BGI, ANF), food (WDRP, CHEF, GPDB), medicines (THCBF, HEWA), household goods (UPPR, RH); Medicine, pharmaceuticals, health care - biotechnology (VKTXW, DMTX, GNLKQ), pharmaceuticals (GMBL, MNZO), honey equipment (ARYC, SMLR, PLSE); Technology sector - Apple (APPL), Nvidia (NVDA), China Intelligence Information Systems (IICN), Genesis Electronics Group (GEGI), Microsoft (MSFT), Google (GOOG); Leisure / Restaurants / Tourism casino (ERI, NNSR, SGMS), hotel and restaurant business (WTBDY, BCCI, UPZC), travel agencies (ACGX, AIOM, BDGN); Automotive sector - General motors (GM), Tesla Inc (TSLA), Harley Davidson (HDL).

Below average volatility: Telecommunication sector - wire communication (LICT, NULM, OTEL), wireless communication (TALK, NTL, MFOYY).

In 2020, the media and entertainment sector, especially HBO, Disney+ and Netflix, the pharmaceutical and medical sector, and the technology sector, thanks to Tesla, became the most popular in the world among investors.

Among investors, the most relevant financial instrument are shares, which are a security that certifies the participation of its owner in the formation of the authorized capital of the company and gives the right to receive a share of its profits in the form of dividends and accumulated capital.

Stock investing strategies are based on the purpose:

- receive a fixed income immediately. To do this, shares with the maximum dividends should be bought. In most cases, these are preferred shares;

- buy shares on the electronic exchange platform and wait until their value increases to sell profitably. In this case, you need to choose stocks with maximum growth potential. Experienced financiers prefer such an investment strategy, as after a steady rise in shares, the proceeds from the sale will significantly exceed the size of any dividends

However, investing in stocks has both advantages and disadvantages. The advantages include reliability, protection against fraud, small amounts at the start of the investment, acceptable liquidity (quite high) and reliability. The disadvantages of stocks can be described as the complexity of investing, because any investment requires an understanding of the process and nuances.

Another disadvantage is the inaccessibility of investing for most Ukrainian investors, despite the fact that although almost everyone can open a brokerage account technically, 
not everyone will be able to put a serious amount on it. The requirements of financial monitoring and the low level of tax culture lead to shadowing of revenues. Because of this, many Ukrainians simply cannot invest in this way.

And the last disadvantage, but very significant - is the risk of losing the value of the asset. Securities can lose quite sharply in price. If, except in case of force majeure, this is not typical for real estate and individual business, then for stocks it is a reality. Unsuccessful financial statements and securities lose in value. Unsuccessful actions of the government and the price of the financial instrument falls. At the same time, the value of securities may not be restored.

Therefore, to choose a financial instrument, both an experienced investor and a beginner need to conduct a thorough analysis and choose the best instruments with minimal risk to themselves.

Today, the IT industry in quarantine is developing the fastest, modernizing and finding ways to move production to remote work. In second place in terms of development is the field of cinema. Many cinema companies are creating online broadcasting services for the library of films and TV programs to compete between companies and attract more consumers.

Financial instruments were selected for comparative analysis - shares of the six most famous companies in the world in the IT sphere and entertainment industry.

Apple Inc. - American technology company with an office in Cupertino (California), which designs and develops consumer electronics, software and online services [21].

Tesla Inc. - American car company - startup from Silicon Valley. Focused on the design, manufacture and sale of electric vehicles and their components. The main production facility is the Tesla plant [22].

Alphabet Inc. - an international conglomerate of companies created on October 2, 2015 by American programmers and entrepreneurs Larry Page and Sergey Brin, which includes Google and other companies they owned directly or through Google [23].

The Walt Disney Company - one of the largest corporations in the entertainment industry in the world. Founded on October 16, 1923 by brothers Walter and Roy Disney as a small animation studio, as of June 2015 it is one of the largest Hollywood studios, the owner of 11 theme parks and two water parks, as well as several television and radio networks, including American Television and Radio $\mathrm{ABC}[24]$.

Netflix Inc. - an American media service provider and production company. As of April 2020, Netflix has 182 million subscribers worldwide, of which 69 million are in the United States. Netflix is available in all countries and regions except mainland China (due to local restrictions), Iran, Syria, North Korea and the Autonomous Republic of Crimea (due to US sanctions). The company also has offices in Brazil, the Netherlands, India, Japan and South Korea. Netflix is a member of the American Film Association [25].

Sony Corporation is one of the world's largest media companies. Sony manufactures consumer and profes- sional electronics and other high-tech products. In addition, Sony is one of the world's largest media companies, with the record label Sony BMG (jointly with Bertelsmann), Columbia Pictures and TriStar Pictures, as well as a complete archive of MGM films (jointly with Comcast) [26].

Stock prices dynamics for the period from September 2017 to September 2020 (daily values) for selected companies can be seen in the figure 1 .

The input data for the study are daily, weekly and monthly prices for the period from $09 / 11 / 2017$ to 09/08/2020 obtained from the site Investing.com [19].

For the selected time series (TS), let's define the following notation:

$$
Z^{i}=\left\langle z_{j}^{i}\right\rangle ; i \in(\overline{1,6}),
$$

where $j \in\{d, w, m\}$, index $d$ denotes daily, $w$ - weekly, $m$ - monthly prices;

$i=1-$ corresponds to the time series of Apple Inc., $i=2-$ time series of Tesla Inc., $i=3-$ time series of Alphabet Inc., $i=4-$ time series of The Walt Disney Company, $i=5$ - time series of Netflix Inc., $i=6$ - time series of Sony Corporation.

\subsection{Results}

For a general understanding of the series dynamics based on the input data, historical volatility is calculated for each selected investment instrument (table 1).

Table 1: Historical volatility of the stock prices

\begin{tabular}{lllllll}
\hline & Apple & Tesla & $\begin{array}{l}\text { Alpha- } \\
\text { bet }\end{array}$ & Disney & Netflix & Sony \\
\hline $\begin{array}{l}\text { Historical } \\
\text { volatility (\%) }\end{array}$ & 40.6 & 107.4 & 39.7 & 40.3 & 43.9 & 81.5 \\
\hline
\end{tabular}

Let's move on to the comparative analysis of the stock markets using the methodology of fractal analysis and calculation of memory depth characteristics. Note that February and March 2020 were the worst months for global stock markets since 2008. Stock indexes lost tens of percent, and experts said that the 11-year growth cycle since the last financial crisis has come to an end.

The cause of the fall - an outbreak of coronavirus, which grew into a pandemic. Against the background of the COVID-19 outbreak, investors have reconsidered their views on the future of the global economy [27]. The restrictive measures introduced in different countries have negatively affected almost all areas related to consumer activity: tourism, trade, catering, entertainment and others. Under quarantine, people spend less and move less. Bidders began to get rid of shares of airlines, oil companies, consumer electronics manufacturers and other companies, waiting for falling income and retvenue. Indices of the world's leading stock exchanges collapsed. For example, the Italian FTSE MIB index alone lost 29.8\% from February 19 to March 11. 


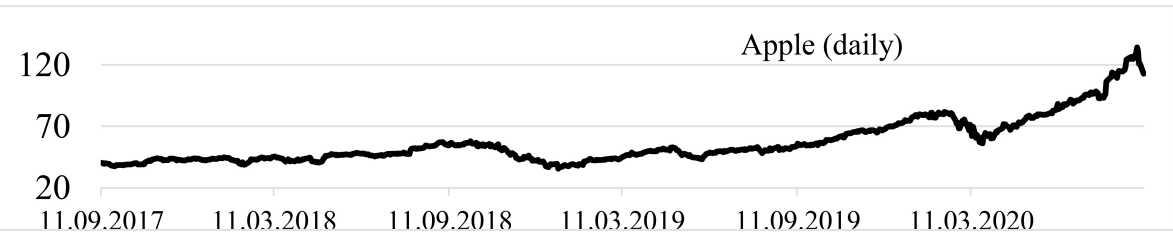

(a)

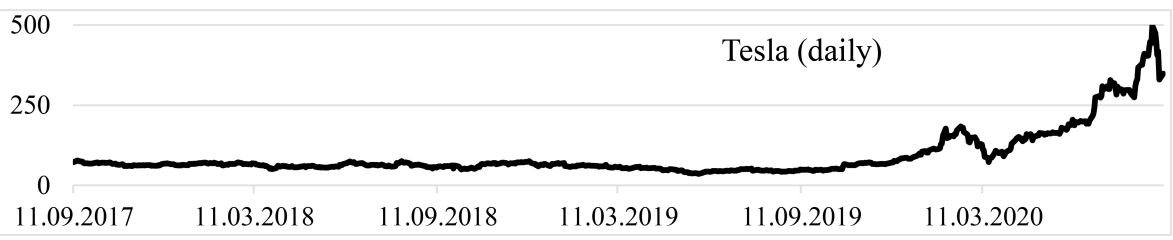

(b)

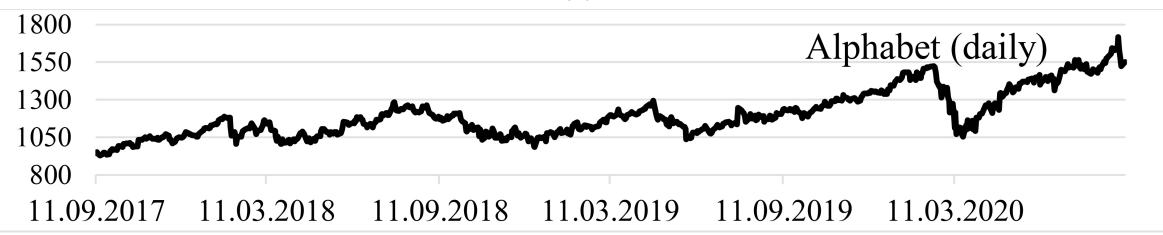

(c)

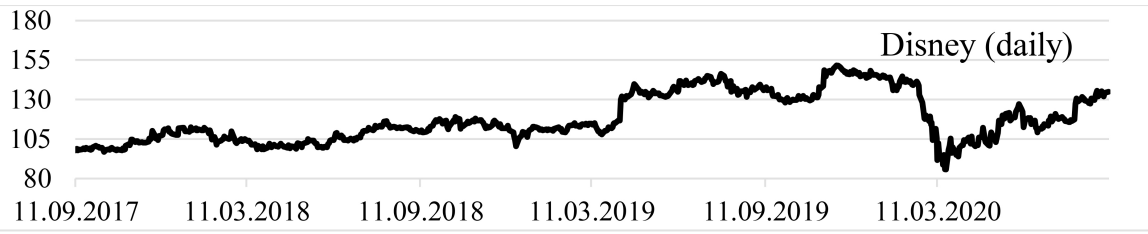

(d)

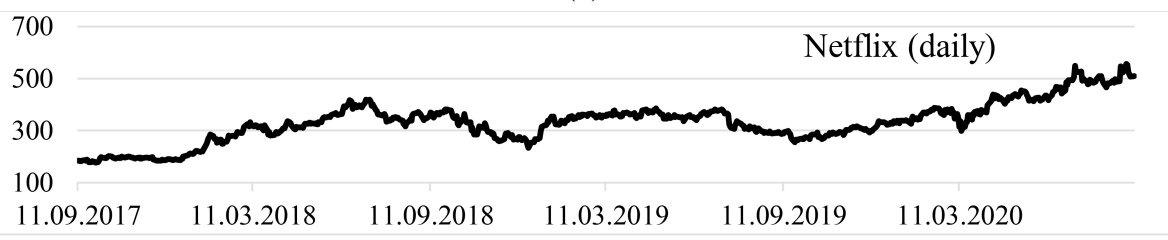

(e)

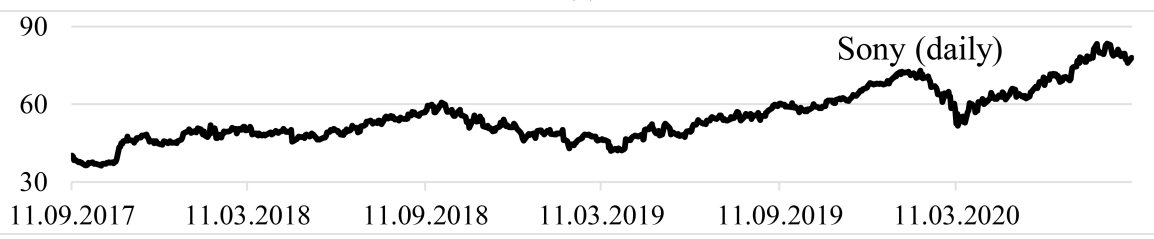

(f)

Figure 1: Stock prices dynamics for the period from September 2017 to September 2020 (daily values) for: a) Apple Inc.; b) Tesla Inc.; c) Alphabet Inc.; d) The Walt Disney Company; e) Netflix Inc.; f) Sony Corporation

In connection with the consequences of the pandemic, the dynamics of stock prices for six corporations before and after the pandemic were analyzed. According to figure 1 , we can see a fairly stable situation of all corporations until 2020, fluctuations in company share prices are quite small, almost imperceptible, but from February to March 2020, this situation is changing.

Consider the obtained values of the Hurst exponent (table 2).

They indicate that all time series throughout the study period from September 2017 to February 2020 are persistent, i.e. have a long-term memory. The value of the Hurst exponent for all time series is in the range $H \in$
$[0.89 ; 0.95]$. For mixed values, the Hurst exponent is in the range $H \in[0.56 ; 0.66]$. The results of fractal analysis TS during a pandemic show that the dynamics of all financial instruments for the entire study period from February 2020 to September 2020 is persistent, i.e. have long-term memory. The value of the Hurst exponent for all time series is in the range $H \in[0.90 ; 0.92]$. For mixed values, the Hurst exponent is in the range $H \in[0.61 ; 0.71]$.

The method of sequential R/S analysis [13] was used to study the dynamics and determine such a characteristic of fractal dynamics as long-term memory (i.e. its depth). As a result, a fuzzy set of memory depth for each TS is constructed. A visual representation of the fuzzy set of 
Table 2: The results of the application of The Hurst's rescaled range method for time series daily prices before the pandemic and during the pandemic

\begin{tabular}{llllll}
\hline TS & $H$ & $H_{\text {mixed }}$ & TS & $H$ & $H_{\text {mixed }}$ \\
\hline \multicolumn{5}{c}{ before the pandemic } \\
\hline$Z_{d}^{1}$ & 0.92 & 0.64 & $Z_{d}^{4}$ & 0.92 & 0.66 \\
$Z_{d}^{2}$ & 0.89 & 0.57 & $Z_{d}^{5}$ & 0.95 & 0.64 \\
$Z_{d}^{3}$ & 0.91 & 0.63 & $Z_{d}^{6}$ & 0.92 & 0.56 \\
\hline \multicolumn{5}{c}{ during the pandemic } \\
\hline$Z_{d}^{1}$ & 0.92 & 0.65 & $Z_{d}^{4}$ & 0.92 & 0.65 \\
$Z_{d}^{2}$ & 0.90 & 0.64 & $Z_{d}^{5}$ & 0.91 & 0.65 \\
$Z_{d}^{3}$ & 0.92 & 0.71 & $Z_{d}^{6}$ & 0.90 & 0.61 \\
\hline
\end{tabular}

Table 3: The results of the application of The Hurst's rescaled range method for time series weekly and monthly prices before the pandemic and during the pandemic

\begin{tabular}{llllll}
\hline TS & $H$ before & $H$ during & TS & $H$ before & $H$ during \\
\hline$Z_{w}^{1}$ & 0.87 & 0.82 & $Z_{w}^{4}$ & 0.87 & 0.86 \\
$Z_{w}^{2}$ & 0.83 & 0.80 & $Z_{w}^{5}$ & 0.91 & 0.85 \\
$Z_{w}^{3}$ & 0.86 & 0.83 & $Z_{w}^{6}$ & 0.87 & 0.84 \\
$Z_{m}^{1}$ & 0.73 & 0.60 & $Z_{m}^{4}$ & 0.80 & 0.56 \\
$Z_{m}^{2}$ & 0.74 & 0.58 & $Z_{m}^{5}$ & 0.80 & 0.66 \\
$Z_{m}^{3}$ & 0.72 & 0.60 & $Z_{m}^{6}$ & 0.74 & 0.60 \\
\hline
\end{tabular}

memory depth on the example of the time series of Apple and Tesla shares is shown in table 4.

Based on the fuzzy memory depth using formulas (3) (6), the following characteristics of the time series dynamics were calculated: the greatest value of the memory depth $l_{\text {max }}$; the gravity center for the fuzzy set of memory depth $l_{g c}$; the most common memory depth $l_{m c}$ and information entropy $\left(H_{\text {entrL }}\right)$ [14]. The results of the calculations are shown in table 5.

When studying the dynamics of stock prices before the pandemic, it was found that for TS $Z_{d}^{1}$ the most often memory is stored for 5 and 6 days, where the gravity center to the fuzzy set of memory depth is 21.8 , and the most common memory depth is 7 , for TS $Z_{d}^{2}$ - during 4 and 5 days, where $l_{m c}=8$ and $l_{g c}=21.7$, for TS $Z_{d}^{3}$ - during 5, 8 days, where the center of gravity is 18.7 , and the memory depth, which is most common from the fuzzy set of memory depths -6 , for TS $Z_{d}^{4}$ - during 6 and 7 days, where the center of gravity is 17.4 , and the memory depth, which is most common from the fuzzy set of memory depth -5 , for TS $Z_{d}^{5}$ - during 6 and 8 days, where $l_{m c}=5$ and $l_{g c}=19.7$, and for TS $Z_{d}^{6}$ - during 5 and 9 days, where the center of gravity is 17.8 and the depth of memory is often 8 , respectively (the number days is given in ascending order of the value of the membership function $\mu, \mu \geq 0.60$ ).

Let's analyze the results of a consistent R/S analysis for the dynamics of stock prices during the pandemic. Long-term memory changed for all tested TS: for TS $Z_{d}^{1}$ the memory is stored for 7 and 11 days, for TS $Z_{d}^{2}-7$ and 9 days, for TS $Z_{d}^{3}-5$ and 8 days, for TS $Z_{d}^{4}-4,5$ and 10 days, for TS $Z_{d}^{5}-8$ and 9 days, and for TS $Z_{d}^{6}-5$ and 7 days (the number of days is given in ascending order of the value of the membership function $\mu, \mu \geq 0.60$ ). According to the results, during the pandemic period, long-term memory in some TS is shifted.

The following conclusions can be drawn from the analysis of the fuzzy set of memory depth.

The most stable and trend-resistant series were TS $Z_{d}^{2}$, $Z_{d}^{3}$ and $Z_{d}^{6}$. For these time series, the $L_{m c}$ indicator is at a relatively high level and does not decrease during the pandemic, which indicates the trend stability of the time series. Shannon's entropy decreases (for TS $Z_{d}^{2}, Z_{d}^{3}$ ), which shows a decrease in uncertainty, or remains unchanged (for TS $Z_{d}^{6}$ ). It should be noted that for TS $Z_{d}^{2}$ the entropy was at the highest level, however, during the pandemic this indicator improved. That is, the crisis in the economy did not affect the increasing uncertainty of the time series.

For TS $Z_{d}^{1}$ negative is a significant decrease in $L_{m c}$ from 7 to 3 . TS $Z_{d}^{4}$ was marked by an increase in the uncertainty (entropy), and for TS $Z_{d}^{5}$, despite the decrease in entropy, $l_{g c}$ and $l_{\text {max }}$ decreased, which showed instability of these series to external risks.

It should be noted that the Hurst exponent of all series is at a high level, which indicates the persistence of the series.

In addition to the fractal analysis of corporate stock prices, we conduct a corresponding analysis of stock profitability.

In this regard, the TSs of stock profitability are built and studied:

$$
P_{s}^{i}=\left\langle p_{s}^{i}\right\rangle
$$

where $i=1-$ corresponds to the time series of Apple Inc., $i=2$ - time series of Tesla Inc., $i=3$ - time series of Alphabet Inc., $i=4-$ time series of The Walt Disney Company, $i=5$ - time series of Netflix Inc., $i=6-$ time series of Sony Corporation;

$p_{s}=\frac{z_{d}-z_{(d-s)}}{z_{(d-s)}} * 100 \%$ - price profitability on day $d$ relative to price on day $(d-s)$, i.e. profitability with lag $s=1,7,10,14,21,28,30,37,42$.

The calculation results of the Hurst exponent for time series of profitability with the lag $1(s=1)$ indicate the randomness of TSs (table 6).

As a result of the study of the time series of the delayed profitability, it was found that the nature of the dynamics of profitability varies from stochastic to persistent depending on the magnitude of the time lag and acquires the characteristics inherent in the "parent" TS of price. But the lag for each time series is different:

TS $P^{1}$ (Apple), $P^{6}$ (Sony) acquire persistence at a $\operatorname{lag}(\mathrm{s})$ value of 14 days, and the Hurst exponent is already 0.70 ;

TS $P^{3}$ (Alphabet), $P^{5}$ (Netflix) acquire persistence at a $\operatorname{lag}(\mathrm{s})$ value of 10 days, and the Hurst exponent is already 0.74 ;

TS $P^{4}$ (Disney) acquires persistence at a $\operatorname{lag}(\mathrm{s})$ value of 7 days, and the Hurst exponent is already equal to 0.71 ;

TS $P^{2}$ (Tesla) acquires persistence at a $\operatorname{lag}(\mathrm{s})$ value of 21 days, and the Hearst index is already 0.70 . 
Table 4: The fuzzy set of memory depth for Apple Inc. and Tesla Inc. stock prices

\begin{tabular}{|c|c|}
\hline Before the pandemic & During the pandemic \\
\hline \multicolumn{2}{|c|}{ The fuzzy set of memory depth for TS $Z_{\delta}^{1}$} \\
\hline 1,00 & 1,00 \\
\hline 0,80 & 0,80 \\
\hline 0,60 & 0,60 \\
\hline 0,40 & 0,40 \\
\hline 0,20 & 0,20 , || \\
\hline 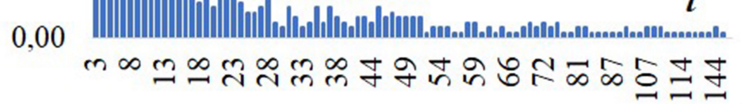 & n,00 \\
\hline \multicolumn{2}{|c|}{ The fuzzy set of memory depth for $Z_{d}^{2}$} \\
\hline 1,00 & $1,00 \mu(l)$ \\
\hline 0,80 & 0,80 \\
\hline 0,60 & 0,60 \\
\hline 0,40 & 0,40 \\
\hline 0,20 & 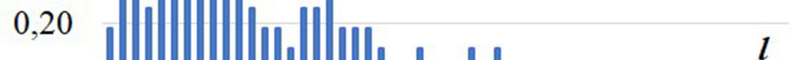 \\
\hline 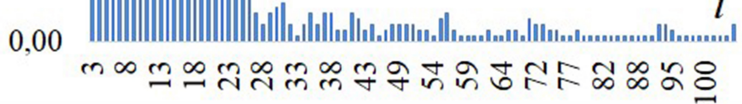 & 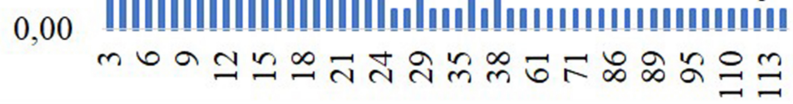 \\
\hline
\end{tabular}

Table 5: The main system characteristics of the fuzzy set of memory depth

\begin{tabular}{|c|c|c|c|c|c|c|c|c|c|c|c|c|}
\hline TS & \multicolumn{2}{|c|}{$Z_{d}^{1}$} & \multicolumn{2}{|c|}{$Z_{d}^{2}$} & \multicolumn{2}{|c|}{$Z_{d}^{3}$} & \multicolumn{2}{|c|}{$Z_{d}^{4}$} & \multicolumn{2}{|c|}{$Z_{d}^{5}$} & \multicolumn{2}{|c|}{$Z_{d}^{6}$} \\
\hline Characteristics & Before & During & Before & During & Before & During & Before & During & Before & During & Before & During \\
\hline$l_{\max }$ & 145 & 154 & 104 & 114 & 153 & 153 & 152 & 138 & 122 & 119 & 154 & 135 \\
\hline$l_{m c}$ & 7 & 3 & 8 & 8 & 6 & 7 & 5 & $4,5,10$ & 5 & 7 & 8 & 8 \\
\hline$l_{g c}$ & 21.8 & 30.8 & 21.7 & 23.8 & 18.8 & 28.1 & 17.6 & 21.4 & 19.7 & 18.8 & 17.9 & 28.3 \\
\hline$H_{\text {entrL }}$ & 22.1 & 20.1 & 23.1 & 18.0 & 19.5 & 17.6 & 18.1 & 20.3 & 20.2 & 16.1 & 18.8 & 18.8 \\
\hline
\end{tabular}

Table 6: The results of the application of The Hurst's rescaled range method for profitability time series before the pandemic and during the pandemic

\begin{tabular}{|c|c|c|c|c|c|}
\hline$\overline{\mathrm{TS}}$ & $H$ before & $H$ after & $\mathrm{TS}$ & $H$ before & $H$ after \\
\hline $\mathrm{Pd} 1$ & 0.62 & 0.59 & $\mathrm{Pd} 4$ & 0.56 & 0.63 \\
\hline $\mathrm{Pd} 2$ & 0.57 & 0.70 & $\mathrm{Pd} 5$ & 0.64 & 0.61 \\
\hline $\mathrm{Pd} 3$ & 0.57 & 0.60 & Pd6 & 0.59 & 0.61 \\
\hline
\end{tabular}

A graphical representation of the values of the Hurst exponent for profitability TS with different lag is shown in figure 2 .

Therefore, the time series $P^{4}$ (Disney) acquires persistence the fastest. We observe that with increasing lag, the Hurst exponent increases and becomes suitable for study by fractal analysis. This allows the investor to unify the analysis tools and forecast profitability in accordance with the characteristics of the price dynamics of a particular investment instrument.

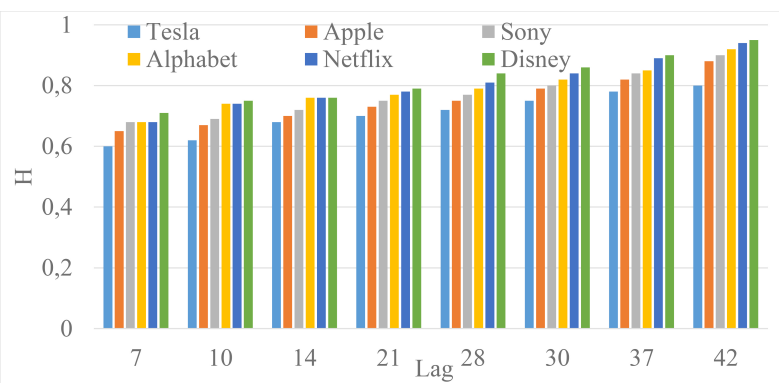

Figure 2: The value of the Hurst exponent for the profitability of shares of Apple, Tesla, Alphabet, Disney, Netflix and Sony with different lags

\section{Conclusions}

Lack of investment strategy can cause loss of funds and complete frustration in the choice of a particular stock market by the investor. To reduce the level of risk, it is necessary to choose how long the wherewithal will be in- 
vested before making the investment. According to the term of investment, there are three strategies: short-term, medium-term and long-term strategy.

Short-term investment can last from a few days to 3 months. The medium term lasts from 3 months to 3 years. Long-term - from 3 years.

The results of the research allow us to offer the following (certain) recommendations for choosing an investment strategy for each selected security.

The first factor for choosing an appropriate strategy for investing in stocks is usually the price and volatility of the security and the sector as a whole. The media and entertainment sectors, automotive and technology have average volatility, ie price change, the rate of change is average. However, the selected financial instruments are characterized by a fairly high historical volatility (table 1). It follows that for all selected financial instruments, we can recommend a short-term investment strategy (table 7) with the possibility of investing for a small period.

Table 7: Choosing an investment strategy

\begin{tabular}{llll}
\hline & $\begin{array}{l}\text { Short-term } \\
\text { strategy }\end{array}$ & $\begin{array}{l}\text { Medium-term } \\
\text { strategy }\end{array}$ & $\begin{array}{l}\text { Long-term } \\
\text { strategy }\end{array}$ \\
\hline Type of analysis & Volatility & $\begin{array}{l}\text { Delayed } \\
\text { profitability }\end{array}$ & $\begin{array}{l}\text { Memory } \\
\text { depth }\end{array}$ \\
\hline Apple & + & ++ & \\
Tesla & + & ++ & ++ \\
Alphabet & ++ & +++ & ++++ \\
Disney & +++ & & \\
Netflix & +++ & & ++ \\
Sony & & & + \\
\hline
\end{tabular}

Netflix and Disney remain the best option for a shortterm strategy, because due to the pandemic, which will cover the world for another one or two years, the stock prices of these companies will be constantly volatile. The price will fluctuate depending on the growth of demand for remote viewing of movies, series and shows, or the return of demand again for watching movies in regular cinemas. As a result, there is a constant risk of losing money if you invest them for more than 3 months.

Consider the second investment strategy - mediumterm. To do this, we turn to the analysis of the results of complex fractal analysis. All series are persistent both before the pandemic and now, ie persistent (tables 2, 3). However, the profitability of instruments is not persistent, and the time series of delayed profitability with different time lag was used to study the level of trend stability (figure 2). Due to which it was determined that Tesla Inc., Apple Inc. and Sony gained the fastest profitability, ie you can invest in these shares for more than a week or two. Because in 7-14 days, the yield becomes persistent and it can be predicted for more than three months. These shares will generate passive income and can be reinvested again. In addition, these corporations are quite ambitious and have grand plans for the future, such as space exploration and shuttle construction, the creation of an electric car, etc., so the prices of their securities will only increase.
Alphabet Inc. has the most stable results, this corporation is often chosen for long-term investment, the results of volatility are the lowest, because the price does not fluctuate strongly enough, the dynamics of the time series is persistent, deferred profitability becomes persistent with a lag of 10 days. The results of the memory depth study show the stability of the corporation even under the influence of natural external factors such as the COVID-19. Stable memory depth characteristics during the pandemic were also demonstrated by shares of Tesla Inc. and Sony (table 7).

Note that these recommendations are formed only on the basis of this study and they may change depending on changes in the dynamics of financial instruments under the influence of various external and internal factors.

\section{References}

[1] E.F. Fama, The Journal of Finance 46, 1575 (1991)

[2] R. Singh, N. Leepsa, N. Kushwaha, Iranian Journal of Management Studies 9, 627 (2016)

[3] C.M. Boya, Research in International Business and Finance 49, 156 (2019)

[4] M.R. Borges, The European Journal of Finance 16, 711 (2010), https://doi .org/10.1080/1351847X.2010.495477

[5] E.E. Peters, Fractal Market Analysis. Applying Chaos Theory to Investment and Analysis (John Wiley \& Sons, Inc., New York, NY, 1994)

[6] L.O. Dittrich, P. Srbek, Atlantic Economic Journal 48, 491 (2020)

[7] V. Soloviev, A. Bielinskyi, O. Serdyuk, V. Solovieva, S. Semerikov, CEUR Workshop Proceedings 2732, 455 (2020)

[8] L.M. Calcagnile, F. Corsi, S. Marmi, Computational Economics 55, 143 (2020)

[9] Y. Karaca, Y.D. Zhang, K. Muhammad, Expert Systems with Applications 144, 113098 (2020)

[10] S. Bianchi, A. Pianese, Chaos, Solitons \& Fractals 109, 64 (2018)

[11] Z. Katarzyna, S. Mikolaj, Analysis of the phenomenon of long-term memory in financial time series, in 36th International Conference on Mathematical Methods in Economics (České Budějovice, Czech Republic, 2018), pp. 216-221

[12] S. Erokhin, O. Roshka, MATEC Web Conf. 170, 01074 (2018)

[13] V. Perepelitsa, N.K.Maksyshko, Analysis and forecasting of the economic systems evolution: problems of data structuring in conditions of uncertainty and pre-forecast analysis (Lambert Academic Publishing GmbH \& Co. KG, Saarbrucken, 2012)

[14] N. Maksyshko, Bulletin of Zaporizhzhia National University 2, 119 (2011)

[15] Z. Tan, Y. Fu, H. Cheng, J. Liu, International Journal of Emerging Markets 23 (2020)

[16] X. Wang, T. Lei, Z. Liu, Z. Wang, Long-memory behavior analysis of China stock market based on 
Hurst exponent, in 2017 29th Chinese Control And Decision Conference (CCDC) (2017), pp. 17101712

[17] H. Tebyaniyan, A. Jahanshad, F. Heidarpoor, International Journal of Nonlinear Analysis and Applications 11, 161 (2020)

[18] C. Chen, Y. Wang, Physica A: Statistical Mechanics and its Applications 466, 346 (2017)

[19] Fusion Media Limited, Investing.com - Stock Market Quotes $\mathcal{F}$ Financial News (2021), https://wWW. investing.com/

[20] Investfunds, Investfunds website about tools for private investors (2020), https: //invest funds.ru/

[21] Apple Inc., Apple (2021), https://www.apple. com/
[22] Tesla, Electric Cars, Solar $\mathcal{E}$ Clean Energy (2021), https://www.tesla.com/

[23] Alphabet, Alphabet (2021), https://abc.xyz/

[24] Disney, The Walt Disney Company (2021), https: //thewaltdisneycompany.com/

[25] Netflix, Watch TV Shows Online, Watch Movies Online (2021), https: //www . netflix. com/

[26] Sony Corporation, Portal site (2021), https:// www. sony.net/

[27] S. Semerikov, S. Chukharev, S. Sakhno, A. Striuk, V. Osadchyi, V. Solovieva, T. Vakaliuk, P. Nechypurenko, O. Bondarenko, H. Danylchuk, E3S Web of Conferences 166 (2020) 